\title{
Os 20 anos da Constituição Federal e as tarefas da pesquisa em direitol
}

\author{
MARCOS NOBRE
}

\section{RESUMO}

O processo constituinte foi marcado por novidades como uma intensa e influente participação da sociedade civil e pela ausência de um bloco hegemônico. Daí o caráter abrangente e detalhista do texto constitucional. Mas foi esse aspecto "contraditório" do texto o que permitiu que fosse reivindicado pelos mais diferentes grupos e movimentos. E foi isso que construiu sua legitimidade e sua vitalidade.

PALAVRAS-CHAVE: Constituição Federal; direito; democracia; disputa política.

\section{SUMMARY}

The Constitutional process was characterized by novelties such as an intense participation of the civil society and the inexistence of a hegemonic block. That's the origin of the broad and detailed character of the Constitutional text. But it was this "contradictory" aspect that allowed it to be vindicated by different groups and movements. And it was this that built its legitimacy and its vitality.

KEYWORDS: Federal Constitution; law; democracy; political dispute.

[1] Conferência proferida no IPEA, Brasília, em 28 de maio de 2008. Pelas críticas e sugestões, agradeço a José Rodrigo Rodriguez, Sérgio Costa, Ricardo Terra, Fernando Rugitsky e Evorah Cardoso. A Marcelo Nobre devo uma importante correção técnica.
É possível que uma boa maneira de realizar uma primeira aproximação do momento histórico da elaboração da Constituição Federal (CF) de 1988 seja mediante um rápido contraste com a situação vivida nos últimos anos por países da América Latina como Bolívia, Equador e Venezuela.

Muito embora tenham experimentado importantes crises institucionais, nenhum desses países saiu recentemente de uma ditadura. Pelo contrário, o que ocorreu foi basicamente a ampliação da participação democrática, com a eleição de figuras identificadas com parcelas pobres da população, historicamente excluídas do processo político. Apesar das tentativas de reduzir essa ascensão das classes populares à representação política a um denominador comum, o fato é que ela assume contornos radicalmente diferentes nos três países mencionados. Mesmo assim, é interessante notar que todos esses processos giram em torno da produção de novas constituições. E isso já deveria ser suficiente para fazer pensarquem ainda hoje sustenta que,em países periféricos, constituições são apenas contos de fada. 
A CF brasileira não apenas foi produzida na saída da ditadura militar. Ela foi elaborada antes de se disseminarem as instituições e práticas democráticas, juntamente com a cultura política que as acompanha. Em certo sentido (um sentido classicamente brasileiro, como se sabe), a CF pressupunha as instituições e práticas que pretendia produzir. Mais que isso, o processo constituinte não esteve condicionado pela presença de um bloco hegemônico que tivesse o poder de impor previamente os limites da disputa política a ser travada, como se pode dizer, por exemplo, de Rafael Correa, no Equador, e, antes dele, de Hugo Chávez, na Venezuela.

Considero a CF de 1988 como expressão de uma crise de hegemonia advinda do fim da ditadura militare da redemocratização². No caso do processo de redemocratização brasileiro, isso significa que o bloco de sustentação da ditadura militar havia se desagregado, não tendo sido capaz de manter o controle da transição. Mas, ao mesmo tempo, não se formou nesse período um bloco alternativo, capaz de dirigir o processo, isto é, capaz de estabelecer de antemão as regras que devem reger a própria disputa política ${ }^{3}$. Com isso, o processo constituinte foi marcado por novidades como uma intensa e influente participação da sociedade civil organizada, um fenômeno de magnitude única na história brasileira. De outro lado, foi marcado igualmente pela ausência de um bloco hegemônico, o que levava as disputas invariavelmente para clinchs políticos 4 .

Daí o caráter abrangente e detalhista do texto constitucional, por exemplo. Daí também a remissão de tantos dispositivos constitucionais para regulamentação posterior. Isso se explica não apenas pelo ambiente de crise de hegemonia em que se deu o processo constituinte, mas igualmente pela perspectiva de cada força política de alcançar posição hegemônica. Pois a exigência de maiorias qualificadas para toda sorte de matérias impunha um engessamento do quadro legal que só poderia ser vencido pela formação de um bloco hegemônico. Esse ambiente de construção institucional resultou em uma transição democrática longa e altamente negociada, marcada por um reformismo bastante limitado.

Essa crise de hegemonia brasileira teve duas formas de expressão mais visíveis. De um lado, a incapacidade de formação de maiorias parlamentares consistentes. De outro, altas taxas de inflação. O pano de fundo mais geral era o da incapacidade de sair de um modelo de desenvolvimento que, na falta de melhor expressão, continuo a chamar de nacional-desenvolvimentista. Nesse sentido, interpreto o período inflacionário da redemocratização não como a realização do ajuste internacional brasileiro, mas, ao contrário, como um adiamento desse ajuste estrutural. Inflação e fragmentação das forças políticas foram dois lados de um mesmo processo de adiamento do ajuste às novas
[2] Para uma exposição mais bem detalhada dessa tese, veja-se o meu artigo "Política difícil, estabilização imperfeita: os anos FHC" (em parceria com Vinicius Torres Freire), Novos Estudos CEBRAP, $\mathrm{n}^{2} 51$, julho de 1998.

[3] Em sociedades democráticas, utilizo a idéia de hegemonia com referência à capacidade de um determinado bloco histórico de estabelecer a pauta e os limites institucionais da disputa política. Em âmbito transnacional, procurei estudar um caso que me parece paradigmático de conquista de hegemonia institucional no livro Desenvolvimento sustentável: a institucionalização de um conceito. Brasília/ São Paulo: Edições IBAMA/CEBRAP, 2002, pp. 21-106.

[4] Por trás da metáfora do clinch, emprestada ao boxe, está a idéia de que, na ausência de um bloco capaz de impor a agenda e os limites para seu debate, a lógica do processo passa a ser regida por pelo menos três componentes: multiplicar demandas, pautas e temas; evitar vetos; e engessar juridicamente os acordos alcançados. A única exceção nesse quadro foram os planos econômicos para combater a inflação, que rompiam o clinch político em nome de sua urgência e premência. Sobre isso, ver adiante. 
[5] Sobre isso, consulte-se o já mencionado "Política difícil,estabilização imperfeita: os anos FHC". formas produtivas do capitalismo. Em certo sentido, é possível dizer que a escalada inflacionária foi uma maneira de manter o processo de redemocratização em andamento. Pois a pressão por fundos públicos vinha de todos os lados do espectro social. E, em um contexto de crise de hegemonia, não é possível impor perdas definitivas a ninguém. A solução (ou não-solução) desse problema levou à hiperinflação.

A superação dessa crise de hegemonia foi um processo de aprendizado econômico e político. Para fins analíticos, talvez valha a pena tentar separar esses dois momentos. Do lado econômico, os fracassos das sucessivas tentativas de estabilização levaram ao aprendizado de que o controle da inflação dependia fundamentalmente de um processo de ampla abertura econômica - entendida não apenas como abertura comercial, mas também como abertura para o investimento. Esse aprendizado levou também à compreensão do fenômeno inflacionário como tendo uma componente inercial decisiva.

Mas a inflação inercial tinha também uma contrapartida política (algo que se poderia chamar de "crise de hegemonia inercial"): somente a construção de um bloco hegemônico poderia levar à superação do modelo nacional-desenvolvimentista e ao controle da inflação. Apesar de ter se apresentado segundo o que se pode chamar de uma "lógica do inevitável" 5 , o governo FHC realizou esses dois movimentos simultâneos em um sentido bem determinado: o Real era tanto plano de estabilização quanto aliança PSDB-PFL.

Foi no bojo desse processo de superação da crise de hegemonia da redemocratização que a Constituição Federal adquiriu progressivamente a legitimidade de que desfruta hoje. Por um lado, ao se propor a difícil tarefa de obter três quintos dos votos nas duas casas do Congresso para alterá-la, o governo $\mathrm{FHC}$ reconhecia a sua importância e legitimidade. Do lado dos opositores às reformas, a defesa do texto original da $\mathrm{CF}$ era invocada contra as alterações propostas. $\mathrm{O}$ mesmo PT que não votou a favor do texto em 1988 passou a defender o texto com afinco na década de 1990. Portanto, se em 1993 a revisão constitucional não se realizou e a CFera ainda largamente considerada como um Frankenstein político-jurídico, dois anos depois ela era considerada referência partilhada por todas as forças políticas do país.

A forma mais visível do que se poderia chamar de "pacto de desigualdade brasileiro" na segunda metade do século XX foi a inflação, conjugada por um longo período a governos autoritários. Para fins argumentativos, reduzo o problema à seguinte equação: a distribuição desigual da riqueza por meio de inflação foi tolerável enquanto o país cresceu a taxas expressivas e a inflação não se tornou hiperinflação. Dito de outra maneira, o pacto de desigualdade mediado por inflação se manteve enquanto foi capaz de assegurar uma melhoria constante nos padrões gerais de vida. Nesse contexto, o Plano Real é um marco 
antes de tudo porque exigiu que o pacto de desigualdade brasileiro fosse refeito em novas bases. A desigualdade distributiva passou a ser sustentada fundamentalmente por mecanismos tributários, fiscais e parafiscais. Mas permanece a condição de que taxas de crescimento constantes possam garantir a melhoria geral das condições de vida.

Esse quadro bastante esquemático me permite dizer que a década de 1980 não foi - como se pensa comumente - a década do ajuste estrutural brasileiro, da adequação às novas condições internacionais, mas foi a década do adiamento desse ajuste, só realizado efetivamente com o Plano Real. E as razões disso hoje são mais claras: foi no contexto recessivo da primeira metade da década de 1980 que se deu a redemocratização brasileira, de modo que a demanda reprimida por participação, serviços e políticas públicos veio à tona de uma só vez. Nesse contexto, uma opção por um ajuste que significasse um aprofundamento ainda maior de políticas recessivas colocaria seriamente em risco a própria redemocratização.

A escalada inflacionária e o descontrole das contas públicas adiaram o ajuste, permitindo a criação das instituições democráticas que vigoram até hoje. Mas seu lado funesto não tardou em se mostrar: uma "guerra de todos contra todos" política que acabou por levar ao precipício da eleição de Fernando Collor. Não sendo possível a formação de um bloco hegemônico, cada grupo tentava isoladamente obter o seu quinhão na distribuição do fundo público, num processo em que qualquer grupo politicamente organizado, seja como força social, seja como partido, seja como uma fração dentro de um partido se colocava como tendo direito de veto. Durante o trabalho constituinte, o máximo de organização política suprapartidária e para além de grupos que se formou foi o então chamado "Centrão", não por acaso o principal pilar de sustentação do futuro governo Collor.

A elaboração e promulgação da CF ocorreram em meio a esse processo. Daí a idéia já mencionada de que o texto constitucional é muito mais uma expressão, uma cristalização da crise de hegemonia própria dos anos 1980 do que um índice de sua superação. $O$ texto foi pensado em grande medida ainda sob inspiração do modelo nacional-desenvolvimentista, por exemplo. Combina elementos aparentemente contraditórios, como a defesa simultânea e concomitante de princípios fundamentais de uma ordem liberal clássica e aqueles típicos do Estado Social da segunda metade do século XX.

Acredito, entretanto, que esse seja um grande mérito da CF de 1988. Primeiramente porque qualquer texto legal estabelece certamente parâmetros para a interpretação, mas não tem sentido unívoco. O sentido último de uma norma jurídica éo resultado de uma disputa interpretativa cuja lógica é fundamentalmente política. Tanto no nível da regulamentação como no da aplicação, as normas ganham sempre 
[6] Não falo em "judicialização da política" porque considero equívoca essa expressão. Dito de maneira breve, porque enfatiza unicamente a decisão judicial, quando o essencial a meu ver está na tradução de demandas em termos jurídicos, de modo que a sua solução é apenas um elemento do processo.Além disso,éimportante lembrar que apenas parte das demandas é traduzida em termos jurídicos, de modo que não cabe hipostasiar esse meio, mesmo reconhecendo sua enorme importância. um rumo interpretativo determinado e nunca definitivo. Foi o caráter largamente "contraditório" do texto constitucional o que permitiu que fosse reivindicado pelos mais diferentes grupos e movimentos. E foi isso que construiu sua legitimidade e sua vitalidade.

Foi esse texto dito "colcha de retalhos", "absurdamente detalhista" e assim por diante o possível para a crise de hegemonia que vivia o país. Mas foi também o mais adequado para a luta posterior pela sua revisão, reforma e pela implementação de direitos. Foi esse seu caráter, digamos, plástico, o que garantiu sua vitalidade. Por essa razão, a CF desempenhou um papel de modelo de juridificação da política ${ }^{6}$. Ao falar em juridificação da política em um contexto de crise de hegemonia quero dizer que o ordenamento jurídico (e a CF em especial) serviu como mecanismo de estabilização da "guerra de todos contra todos" dos 1980. Claro que esse novo papel do direito no Brasil só se tornou possível com a redemocratização. Durante breves períodos o direito foi levado a sério no Brasil. E por boas razões, já que tivemos ditaduras e/ou coronelismo durante mais de metade do século XX.

O processo constituinte fez com que todas as forças políticas passassem a recorrer ao direito para conquistar e preservar espaços na luta por direitos e por fundos públicos. Esse modelo se consagrou pelo recurso ao estabelecimento de cotas constitucionais dos orçamentos, por exemplo. Como a modificação desses dispositivos é muito complexa e difícil, o seu significado mais imediato é o de limitar significativamente o espaço de disputa política.É um tipo de lógica que vai levar a remendos constitucionais que permitam uma maior flexibilidade na execução orçamentária, tais como o Fundo Social de Emergência, primeira de todas as emendas de revisão, depois substituído pelo Fundo de Estabilização Fiscal e, finalmente, pela Desvinculação de Recursos da União (DRU).

Em suma, o processo político brasileiro desde os 1980 pode ser caracterizado pela restrição cada vez maior dos fundos públicos em disputa. A lógica subjacente é a de que o sistema político é incapaz de produzir maiorias sólidas e constantes, de modo que o essencial do orçamento (reservas constitucionais e pagamento da conta de juros) tem de ficar de fora da disputa por recursos. A DRU é hoje o único desafio legislativo anual importante de um governo no Brasil.

A fixação prévia da distribuição de fundos públicos sob a forma de um engessamento legal dos recursos orçamentários e do alto estoque de dívida pública levam as disputas a se dar hoje sobre margens. Isso quer dizer também que a superação da crise de hegemonia, com os dois mandatos de FHC, não se deu no sentido de uma reorganização institucional radicalmente nova. Pelo contrário, a grande novidade da era FHC foi justamente a de construir parâmetros institucionais para organizar e consolidar o engessamento político que veio com a redemocratização. 
Foi assim queestabilidade se tornou sinônimo de "responsabilidade fiscal”, por exemplo. São pelo menos três as conseqüências disso.

Em primeiro lugar, deslocam as disputas reais da elaboração para a execução do orçamento, o que torna os Ministérios e o Executivo de maneira mais geral centros de poder muito mais efetivos a esse respeito. Isso leva a barganhas permanentes entre os Ministérios e o Congresso, em negociações de dia-a-dia que estão praticamente fora da luz do debate público.

Em segundo lugar, esse processo embasa a tese muito difundida da prevalência do Executivo sobre o Legislativo e o Judiciário, e também mostra a lógica da construção de alianças políticas, na qual uma força política só adquire poder se consegue Ministérios importantes.

Em terceiro lugar, mas não menos importante, essa maneira peculiar de engessar as disputas leva também o debate público a uma espécie de círculo enlouquecido. Como as margens de manobra são muito estreitas, os "suspeitos de sempre" desse típico clinch político brasileiro aparecem e reaparecem periodicamente. A legislação trabalhista éo grande problema em março e abril, a reforma política é o tema de maio e junho, a previdência toma julho e agosto e setembro e outubro são meses de reforma tributária. E assim por diante.

Não estou querendo dizer que esses problemas não sejam reais. Quero apenas chamar a atenção para essa espécie de "coerção à repetição" que nunca vai às causas. É uma ilusão achar que não se avança nessas ditas reformas porque "não há vontade política". O sistema político está fundado na idéia de que os clinchs são inevitáveis. Por essa razão as decisões vão ser tomadas seja pelo Executivo seja pelo Judiciário e não porque não "há vontade política". Também não é uma reforma específica que vai resolver isso. O clinch é expressão de uma sociedade politicamente travada, não há nada de artificial nele. Eé só a sociedade que pode resolvê-lo, não uma reforma qualquer.

Esse retrospecto esquemático me parece necessário para caracterizar a diferença entre as reformas do período FHC e o momento atual. As reformas realizadas foram essencialmente relativas à ordem econômica e reformas fiscais de maneira mais geral. A situação atual me parece marcada não apenas pela consolidação da CF como instrumento legítimo de disputa política, reconhecida pela grande maioria dos atores políticos, mas também pela mudança de foco da disputa.

Não me parece que uma nova grande onda de reformas constitucionais esteja agora no horizonte. A disputa no momento me parece se deslocar para a legislação complementar, em seus vários aspectos, em questões mais gerais de implementação de direitos inclusive. Não quero dizer com isso que uma nova onda de reformas constitucionais não possa vir a se formar. Digo apenas que, no momento atual, isso me parece extremamente improvável. Primeiro, porque a 
formação de maiorias de três quintos no Congresso em favor de uma série de Propostas de Emenda Constitucional (PEC) que introduzam mudanças estruturais parece dificilmente alcançável, seja para este governo, seja para qualquer governo, tendo em vista a atual configuração dos blocos político-partidários consolidados. Em segundo lugar, porque a sociedade organizada descobriu o Judiciário e os espaços de regulamentação do Executivo como importantes nichos de disputa, sendo que, no Legislativo, busca a criação de leis que exijam maioria e não quoruns qualificados. Em terceiro lugar, porque já ficou claro que uma alteração constitucional (como qualquer produção legislativa, aliás) não garante que sua aplicação vá se dar automaticamente, como se o sentido do texto fosse evidente por si mesmo. Pelo contrário, fica a cada dia mais evidente que a disputa política tem de se dar em todos os níveis de propositura, criação da lei e aplicação. Só a jurisprudência e, em última instância, uma decisão dos tribunais superiores pode estabilizar (pelo menos por algum tempo) esse sentido.

Nesse sentido, a CF também deixou de ser fetiche, o que é bom. É bom que uma Constituição não seja encarada com um texto sagrado, mas como um texto vivo que pode ser modificado, cujo sentido depende da disputa política. Juristas de renome que costumam gritar aos quatro ventos que algo é inconstitucional não estão fazendo nada mais do que entrar em uma disputa política pelo sentido do texto se utilizando do prestígio profissional e acadêmico de que dispõem. Chavões da esfera pública brasileira, como "constituição boa é a que se muda pouco" parecem sem sentido. Não apenas porque parecem partir do pressuposto de que direito bom é direito sagrado e intocável, mas também porque não correspondem ao que efetivamente ocorre. Constituições são alteradas freqüentemente e não necessariamente por mudanças no texto constitucional. Os EUA, em geral tomados como modelo e parâmetro, não são diferentes: a Suprema Corte trata de alargar a interpretação dos artigos existentes para incorporar novos direitos sociais e políticos, por exemplo. Também um outro chavão como "decisão judicial não se discute, cumpre-se" parece partir do mesmo pressuposto problemático: afinal, em que a discussão aberta de uma discussão judicial atrapalha o seu cumprimento?

Em favor dessa interpretação, invoco o fato de que muita matéria constitucional está sendo tratada e resolvida por outros caminhos. Um exemplo claro disso hoje me parece ser o que envolve o instituto da Medida Provisória (MP). Sem alterar o texto constitucional, a Câmara dos Deputados eo Senado Federal estão buscando acordos para o rito de tramitação de MPs. E o Supremo Tribunal Federal (STF) também já se pronunciou sobre a matéria, inaugurando mais uma disputa sobre a interpretação da medida liminar 
que suspendeu a MP 405, que abriu crédito extraordinário para a justiça eleitoral e órgãos do poder Executivo: a decisão diz respeito apenas à MP objeto da ação ou vale de maneira geral para qualquer MP? Ou ainda: para qualquer MP cujo conteúdo diga respeito a créditos extraordinários?

Dito de outra maneira, parece que a primeira onda de reformas constitucionais se encerrou e que estamos em meio a uma segunda onda de disputas constitucionais, em que o texto constitucional nãoé o objeto direto da disputa, mas o seu objeto pressuposto, já que regulamentações e implementações estão referidas necessariamente à CF à qual devem sua origem e sua legitimidade.

Duas observações sobre isso. Em primeiro lugar, acredito que, independentemente do seu conteúdo e de seu mérito, o processo de reformas já realizado consolidou a CF como legítima carta constitucional, referência do debate. Em segundo lugar, acredito que a segunda onda de discussões constitucionais será bastante diferente da primeira: muito menos mudanças do texto constitucional e muito mais discussões infraconstitucionais, de regulamentação e implementação. Isso não significa que sejam menos importantes. Significa apenas que se dirigirão à obtenção de maiorias apertadas (e não mais aos três quintos exigidos para uma alteração constitucional) e que ocuparão por igual não apenas o espaço do Congresso Nacional (como foi o caso da primeira onda de reformas), mas também o Executivo e seus espaços de regulamentação e decisão e, sobretudo, o Judiciário, em especial os tribunais superiores. E isso não apenas no que se refere aos cerca de 50 artigos constitucionais que ainda aguardam regulamentação, extremamente urgente em alguns casos.

Considero importante destacar as novidades dessa nova etapa de discussões constitucionais. Em primeiro lugar, instrumentos jurídicos que não receberam a atenção investigativa devida passam a ser centrais, como é o caso das Ações Civis Públicas. Como a legitimidade da propositura desse tipo de ação cabe em princípio ao Ministério Público, a associações ou representantes de grupos ou classes, a pesquisa sobre a efetivação, regulamentação e implementação de direitos sociais parece encontrar aqui um locus privilegiado.

Além disso, já têm e tendem a ganhar cada vez mais destaque direitos e políticas que eu gostaria de chamar aqui de reconhecimento, uma denominação que me parece mais ampla e mais adequada do que o termo "ações afirmativas". Basicamente, a idéia é a de que a garantia do exercício de determinadas liberdades depende de condições de igualdade que se encontram ausentes; mas essas condições não são apenas materiais, de modo que a promoção da igualdade nesse caso depende de um reconhecimento social da igualdade que não pode ser obtido unicamente por meio do seu estabelecimento jurídico. Em suma, o 
[7] Ver a esse respeito o meu artigo "Apontamentos sobre a pesquisa em Direito no Brasil", Novos Estudos CEBRAP, $\mathrm{n}^{\mathrm{e}} 66$, julho de 2003.
[8] Em vista da instabilidade do texto constitucional nos últimos vinte anos, tornou-se extremamente difícil para uma Corte Constitucional elaborar uma interpretação coerente e abrangente da Carta. Note-se a esse respeito que, no exercício de sua função de Corte Constitucional desde 1988, o STF freqüentemente não se pronunciou sobre o mérito das ações. Se estiver correta a idéia de que o texto $\mathrm{da} \mathrm{CF}$ encontrou agora uma relativa estabilidade, torna-se plausível que a atividade do STF passe a ser primordialmente a de sua função de Corte Constitucional. direito éentendido aqui como veículo de uma promoção social que vai muito além dele. É nesse sentido que "políticas de reconhecimento" parece uma expressão muito mais adequada ao objeto do que "ações afirmativas" ou mesmo "discriminação positiva".

Se estiver correto esse diagnóstico e esse prognóstico, as tarefas teóricas que se colocam para a pesquisa se dirigem primordialmente para o acompanhamento de instâncias de disputa jurídicas (e não apenas judiciais) da implementação e regulamentação de dispositivos constitucionais. Não vou me estender aqui sobre as dificuldades desesperadoras com que se vê defrontado quem faz pesquisa em direito no Brasil7. Gostaria apenas de apontar para alguns campos de pesquisa que parecem tão necessários quanto promissores.

Se o diagnóstico apresentado aqui estiver correto no sentido de que o momento é de relativa estabilidade do texto constitucional, é possível prever que a disputa do seu sentido vai se deslocar agora primordialmente para o Judiciário. Uma evidência clara disso parece ser a disposição coletiva no interior do STF para enfrentar em série casos difíceis e paradigmáticos de interpretação. Se essa percepção estiver correta, o STF irá progressivamente assumir mais e mais a sua função de Corte Constitucional, tarefa que tinha sido até recentemente relegada a segundo plano em favor da sua função de última instância do Judiciário ${ }^{8}$. Com isso, será possível pela primeira vez desde a promulgação da $\mathrm{CF}$ falar na produção de uma série de precedentes interpretativos no sentido preciso de precedentes que podem ser unificados em uma interpretação de conjunto coerente do texto constitucional.

Ocorre que essa transformação do STF não virá sem conflito. Tanto porque, corretamente, o STF está-se abrindo a receber novas contribuições e opiniões (com a realização de audiências públicas e a maior participação de terceiros nos processos), como por duas outras razões relevantes. Em primeira linha, o conflito no interior do próprio STF.A perspectiva de que seja possível unificar os votos dos ministros sobre determinada matéria parece pouco provável. Nesse sentido, o próprio tribunal terá em algum momento de chegar a um acordo sobre o que deva ser se constituir em um precedente, já que, hoje, tem-se o voto do ministro relator, votos favoráveis ou contrários que fundamentam de maneira diversa a tese favorável ou contrária ao relatório e o próprio placar da votação.

Além disso, porém, há ainda o conflito que irá seestabelecer com as instâncias inferiores do próprio Judiciário. Pois o sistema de controle constitucional brasileiro, por ser misto, garantiu sempre aos tribunais inferiores a possibilidade de se pronunciarem sobre temas constitucionais em caráter decisório. Como o STF permaneceu vinte anos atuando apenas na margem de sua função de Corte Constitucional, a quantidade de decisões e de interpretações produzidas pelas ins- 
tâncias inferiores e por doutrinadores foi muito significativa. Nesse sentido, se é pacífico que cabe ao STF produzir uma imagem íntegra $\mathrm{da} \mathrm{CF}$, o material a que terá de recorrer para tanto foi forjado em grande medida pelos tribunais inferiores. E estes continuarão a disputar a interpretação da CF, seja qual for o encaminhamento dado pelo STF.

É difícil dizer se tal imagem íntegra da CF será mesmo produzida pelo STF no curso dos próximos anos, ou se, ao contrário, o tribunal acabará se perdendo em disputas intestinas, ou mesmo se uma "guerrilha" mais ou menos organizada por parte dos tribunais inferiores virá a impedir a formação de uma tal interpretação de conjunto. Isso dependerá em grande medida da capacidade dos atores envolvidos em convencer os operadores do direito ea opinião pública da superioridade de suas posições. O queé certo é que a relativa estabilidade do texto constitucional pede urgentemente que se dediquem esforços de pesquisa para a compreensão de como funciona concretamente o Judiciário brasileiro, para além do folclore, das lendas e das ilusões interessadas.

MARCOS NOBRE é professor no Departamento de Filosofia da Unicamp e pesquisador do Cebrap e do CNPq.

Recebido para publicação em 15 de outubro de 2008.

\section{NOVOS ESTUDOS}

CEBRAP

82, novembro 2008

pp. 97-106 